\title{
A New Closed-Form Solution of the Side Abutment Pressure Distribution of Roadway
}

\author{
Liang Cheng $\mathbb{D}^{1}$ and Yidong Zhang $\mathbb{D}^{2}$ \\ ${ }^{1}$ School of Mines, Key Laboratory of Deep Coal Resource Mining, Ministry of Education of China, \\ China University of Mining and Technology, Xuzhou 221116, China \\ ${ }^{2}$ School of Mines, State Key Laboratory of Coal Resources and Safe Mining, China University of Mining and Technology, \\ Xuzhou 221116, China \\ Correspondence should be addressed to Yidong Zhang; ydzhang@cumt.edu.cn
}

Received 10 May 2018; Accepted 3 July 2018; Published 1 August 2018

Academic Editor: Libo Yan

Copyright (C) 2018 Liang Cheng and Yidong Zhang. This is an open access article distributed under the Creative Commons Attribution License, which permits unrestricted use, distribution, and reproduction in any medium, provided the original work is properly cited.

\begin{abstract}
Instability of coal wall is one of the hot-button and difficult issues in the study of coal mine ground control. The shallow side coal of roadway in the coal measures is usually weak and consequently easy to bring about failure. Hence, the side abutment pressure redistributes and dramatically influences the roadway stability. Since the previous closed-form solutions of the side abutment pressure do not take into account all the necessary parameters which include the properties of the coal and the interface between coal and roof/floor, the roadway height, and the support strength, a mechanical model is established based on the equilibrium of the plastic zone, and a new closed-form solution is derived in this paper. Moreover, a numerical investigation is conducted to validate the accuracy of the closed-form solution. The numerical results of the side abutment pressure distribution are in good agreement with the closed-form solution. Afterwards, a parametric analysis of the width of the plastic zone is carried out, and the results show that the width of the plastic zone is nearly negatively linearly correlated with the friction angle and the cohesion of the coal, the interfacial cohesion, and the support strength. By contrast, it is positively linearly correlated with the roadway height and negatively exponentially correlated with the interfacial friction angle. The results obtained in the present study could be useful for the evaluation process of roadway stability.
\end{abstract}

\section{Introduction}

Underground coal is an integral part of the primary energy sources and is used for a wide range of applications. Physical extraction of coal is still an important method in the mining industry. Before the physical extraction, a group of roadways needs to be constructed for the transportation of the workers, equipment, tools, and raw coal. Along with the mining production, the excavation of roadway is continuing. Therefore, to some extent, the stability of roadway has a large effect on the efficiency of underground coal mining.

The roadway stability is dramatically influenced by the abutment pressure distribution [1-3]. The stress distribution of surrounding rock of roadway could be calculated by using elasticity when it is assumed that the surrounding rock follows the assumptions of elasticity [4]. However, roadway is excavated in a coal seam, and the shallow coal is usually weak and consequently easy to bring about failure $[5,6]$. Neither the laws of soil mechanics nor the theories of elasticity explain completely the behavior of the relatively soft coal [7]. In this condition, the side abutment pressure distribution can be obtained roughly based on the closedform solutions of (1) (4) and (7) in Table 1 [8-10]. The above closed-form solutions neglect the interface between coal and roof/floor. Actually the interface between coal and roof/floor is usually weak and has a large effect on the side abutment pressure distribution, which usually degrades roadway stability. Shou demonstrated that the lesser angle between the axial direction of the entry and the dip direction of the weak plane contributed larger deformation for the roof [11]. Jeon et al. found that the shear deformation at the weak plane leads to a large displacement of the rock around the entry [12]. Zhao et al. revealed that the shear slipping mainly occurred along the weak plane due to the failure of 

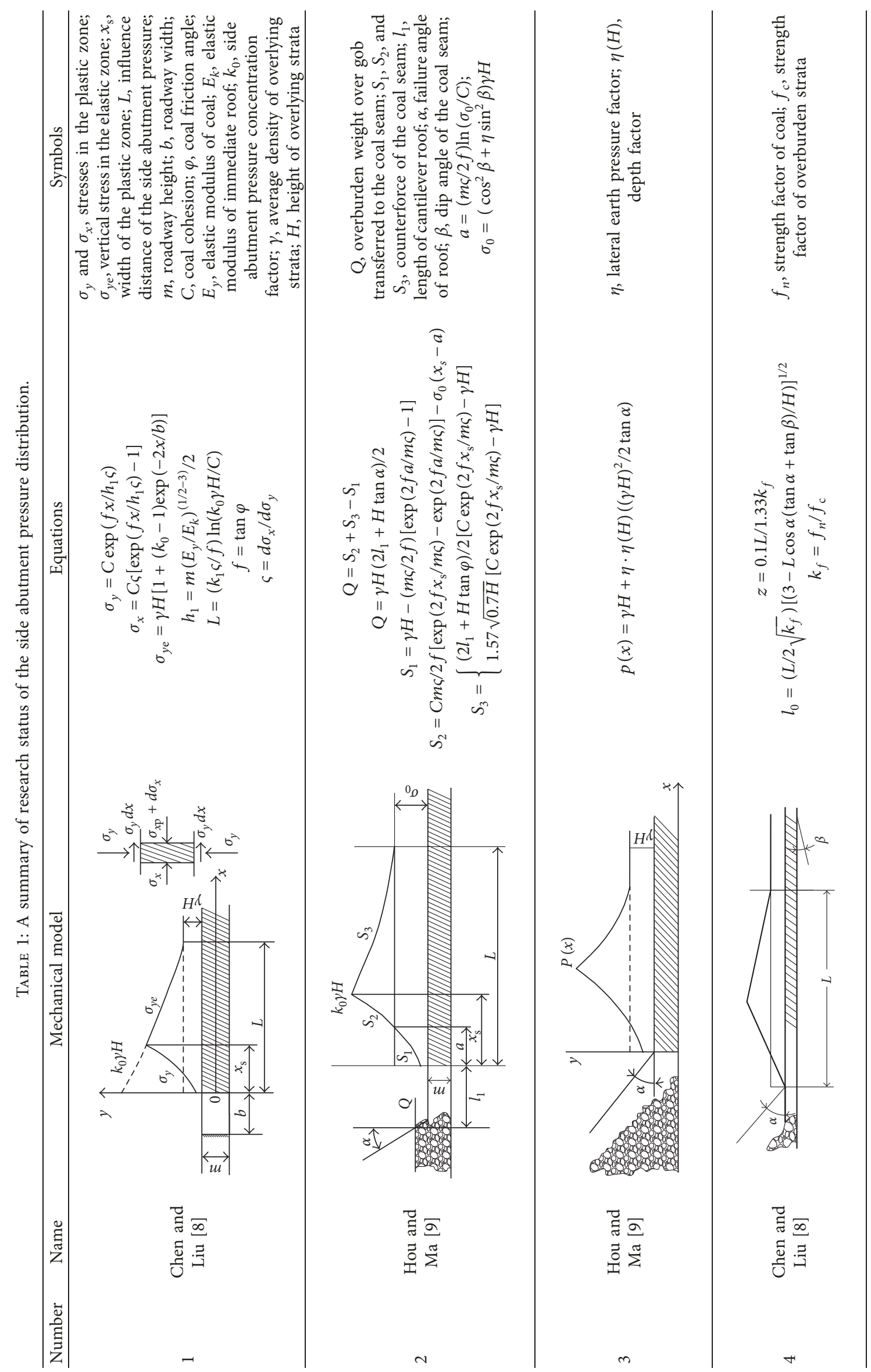


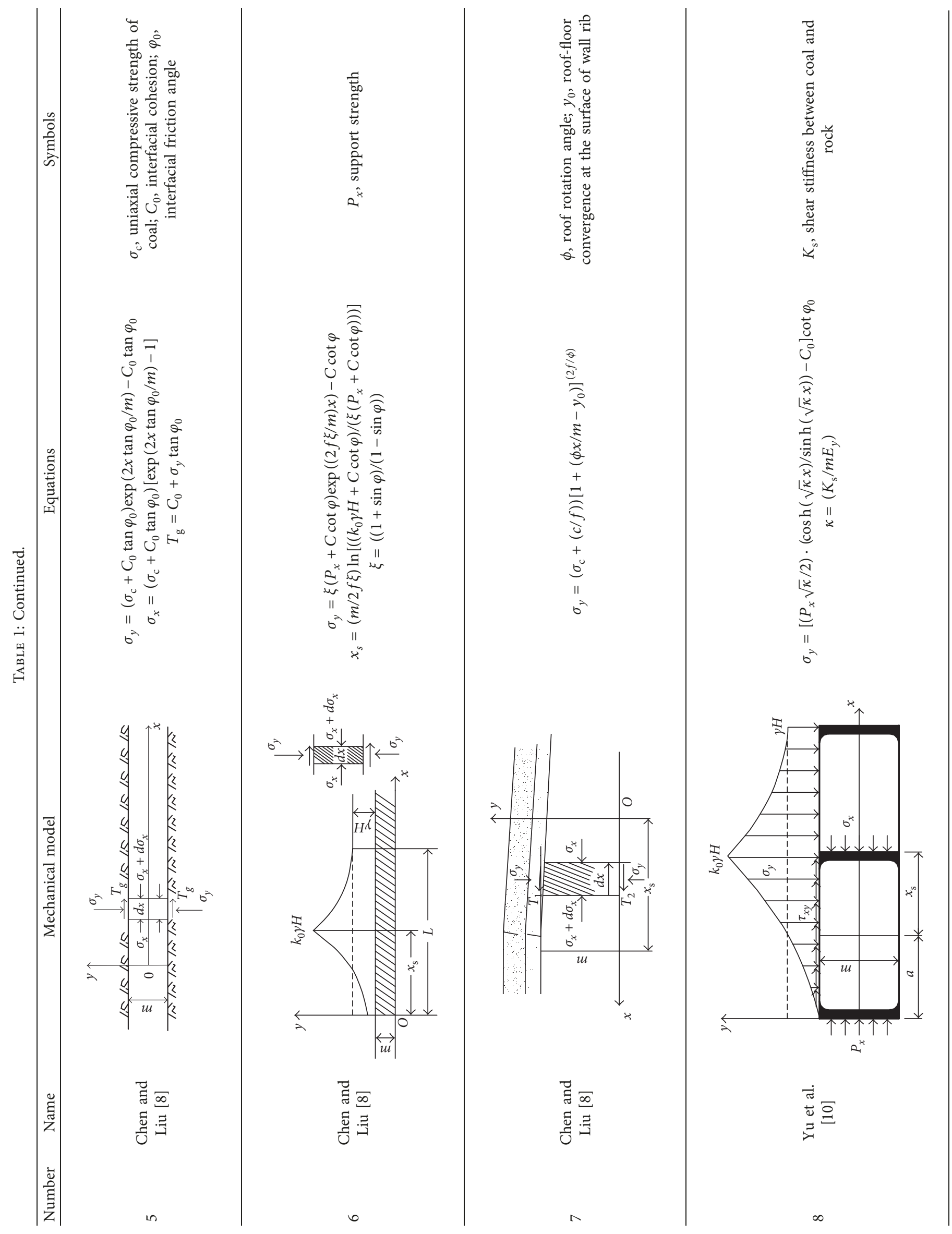




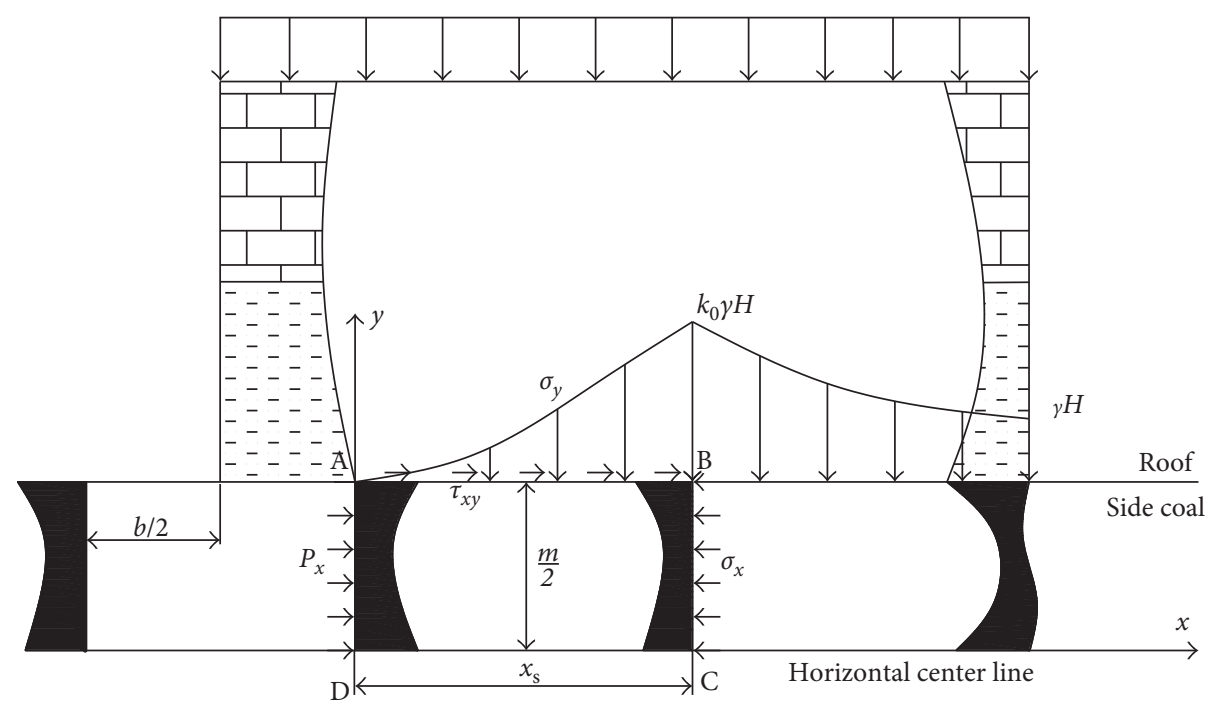

Figure 1: Mechanical model.

weak plane [13]. Zhao et al. pointed out that the coal-rock combination with weak interface trended to isotropic rock when the confining pressure is raised to a specific value [14]. Shen et al. indicated that the side abutment pressure could result in a relative displacement for entry roof with the weak plane $[2,15]$. Taking into account the interfacial properties, the closed-form solutions (5), (6), and (8) in Table 1 [8-10] were derived.

Although the closed-form solutions in Table 1 revealed some characteristics of the side abutment pressure distribution, none of these closed-form solutions include all the necessary parameters which include the properties of the coal, the properties of the interface between coal and roof/floor, the roadway height, and the support strength. To overcome the deficiency of the closed-form solutions of the side abutment pressure distribution, a new closed-form solution was derived in the paper. Moreover, the accuracy of the closed-form solution was validated by modelling.

\section{Calculation}

2.1. Mechanical Model. The side abutment pressure redistributes after roadway excavation. The coal in the plastic zone subjects to limit equilibrium state and deforms toward to the roadway. Therefore, the shear stress occurs along the interface. The mechanical model is shown in Figure 1.

2.2. Basic Assumptions. To solve this problem, several assumptions are made as follows: (1) The roadway height is equal to the thickness of the coal seam. (2) The support strength distributes evenly at the wall surface. (3) The effect of the failure of roof/floor on the coal is neglected. (4) The dead weight of the coal is neglected. (5) The properties of the coal and the interface remain the same after yielding. (6) The shear stress at the horizontal center line of the plastic zone is zero. (7) The interface is perfectly elastic-plastic and follows Mohr-Coulomb failure criterion.

$$
\tau_{x y}=-\left(\sigma_{y} \tan \varphi_{0}+C_{0}\right)
$$

where $\tau_{x y}$ is the shear stress. (8) The constitutive model of the coal follows Mohr-Coulomb failure criterion. (9) The maximum vertical stress is given by

$$
\sigma_{y}=k_{0} \gamma H \text {. }
$$

\subsection{Theoretical Calculation}

2.3.1. The Interfacial Stress. The basic equation of the coal is expressed by

$$
\begin{aligned}
& \frac{\partial \sigma_{x}}{\partial x}+\frac{\partial \tau_{x y}}{\partial y}=0 \\
& \frac{\partial \sigma_{y}}{\partial y}+\frac{\partial \tau_{x y}}{\partial x}=0
\end{aligned}
$$

Substituting (1) into (4) yields

$$
-\frac{\partial \sigma_{y}}{\partial x} \tan \varphi_{0}+\frac{\partial \sigma_{y}}{\partial y}=0 .
$$

The vertical stress could be assumed as follows:

$$
\sigma_{y}=f(x) g(y)+W_{1} \text {. }
$$

From (5), it can be assumed that

$$
\frac{f^{\prime}(x)}{f(x)} \tan \varphi_{0}=\frac{g^{\prime}(y)}{g(y)} .
$$

Assuming that (7) is equal to a constant of $W_{2}$, the following equation can be obtained:

$$
\begin{aligned}
\frac{f^{\prime}(x)}{f(x)} \tan \varphi_{0} & =W_{2}, \\
\frac{g^{\prime}(y)}{g(y)} & =W_{2} .
\end{aligned}
$$


Solving (8) gives

$$
\begin{aligned}
& f(x)=W_{3} \exp \left(\frac{W_{2}}{\tan \varphi_{0}} x\right), \\
& g(y)=W_{4} \exp \left(W_{2} y\right) .
\end{aligned}
$$

Substituting (9) into (6) yields

$$
\sigma_{y}=W_{5} \exp \left(\frac{W_{2}}{\tan \varphi_{0}} x\right)+W_{1},
$$

where $y=m / 2 ; W_{5}=W_{3} W_{4} \exp \left(\left(W_{2} m\right) / 2\right)$; and $m$ is the roadway height.

Substituting (10) into (1) yields

$$
\tau_{x y}=-\left\{\left[W_{5} \exp \left(\frac{W_{2}}{\tan \varphi_{0}} x\right)+W_{1}\right] \tan \varphi_{0}+C_{0}\right\} \text {. }
$$

2.3.2. The Equation of Limit Equilibrium Zone. Based on the mechanical model in Figure 1, the resultant force in the limit equilibrium zone ABCD is zero.

$$
\frac{m}{2} \sigma_{x}+\int_{0}^{x} \tau_{x y} d x-\frac{m}{2} P_{x}=0
$$

where $P_{x}$ is the support strength.

The interfacial friction angle and cohesion are much lower than that of coal. Therefore, the vertical and horizontal stress in the plastic zone are assumed as the principle stresses, and the relationship is shown as follows based on Mohr-Coulomb failure criterion:

$$
\sigma_{x}=\sigma_{y} \frac{1-\sin \varphi}{1+\sin \varphi}-\frac{2 C \cos \varphi}{1+\sin \varphi} .
$$

The derivation of each side of (12) is as follows:

$$
\frac{m}{2}\left(\frac{1-\sin \varphi}{1+\sin \varphi}\right) \frac{d \sigma_{y}}{d x}+\tau_{x y}=0
$$

Substituting (1) into (14) yields

$$
\frac{m}{2}\left(\frac{1-\sin \varphi}{1+\sin \varphi}\right) \frac{d \sigma_{y}}{d x}-\tan \varphi_{0} \sigma_{y}-C_{0}=0 .
$$

Solving (15) yields

$$
\sigma_{y}=W_{6} \exp \left[\frac{2 \tan \varphi_{0}(1+\sin \varphi)}{m(1-\sin \varphi)} x\right]-\frac{C_{0}}{\tan \varphi_{0}} .
$$

2.3.3. The Side Abutment Pressure Distribution in Plastic Zone. Comparing (10) and (16) gives

$$
\begin{aligned}
& W_{5}=W_{6}, \\
& W_{2}=\frac{2 \tan ^{2} \varphi_{0}}{m}\left(\frac{1+\sin \varphi}{1-\sin \varphi}\right), \\
& W_{1}=-\frac{C_{0}}{\tan \varphi_{0}} .
\end{aligned}
$$
yields

$$
\begin{aligned}
W_{6} \exp \left[\frac{2 \tan \varphi_{0}(1+\sin \varphi)}{m(1-\sin \varphi)} x\right]-\frac{C_{0}}{\tan \varphi_{0}}=k_{0} \gamma H \\
\frac{m}{2}\left(\sigma_{y} \frac{1-\sin \varphi}{1+\sin \varphi}-\frac{2 C \cos \varphi}{1+\sin \varphi}\right)+\int_{0}^{x} \tau_{x y} d x-\frac{m}{2} P_{x}=0 .
\end{aligned}
$$

Integrating $x$ in (11) yields

$\int_{0}^{x} \tau_{x y} d x=\frac{W_{6} m(1-\sin \varphi)}{2(1+\sin \varphi)}\left\{1-\exp \left[\frac{2 \tan \varphi_{0}(1+\sin \varphi)}{m(1-\sin \varphi)} x\right]\right\}$.

Equation (18) can be rewritten as follows:

$$
\begin{aligned}
W_{6} \exp \left[\frac{2 \tan \varphi_{0}(1+\sin \varphi)}{m(1-\sin \varphi)} x\right]-\frac{C_{0}}{\tan \varphi_{0}}=k_{0} \gamma H, \\
k_{0} \gamma H \frac{1-\sin \varphi}{1+\sin \varphi}-\frac{2 C \cos \varphi}{1+\sin \varphi}+\frac{W_{6}(1-\sin \varphi)}{1+\sin \varphi} \\
\cdot\left\{1-\exp \left[\frac{2 \tan \varphi_{0}(1+\sin \varphi)}{m(1-\sin \varphi)} x\right]\right\}-P_{x}=0 .
\end{aligned}
$$

Solving (20) yields

$$
W_{6}=\frac{C_{0}}{\tan \varphi_{0}}+\left(\frac{1+\sin \varphi}{1-\sin \varphi}\right) P_{x}+\frac{2 C \cos \varphi}{1-\sin \varphi} .
$$

Substituting separately (17) and (20) into (10) and (11) yields

$$
\begin{aligned}
\sigma_{y}= & {\left[\frac{C_{0}}{\tan \varphi_{0}}+\left(\frac{1+\sin \varphi}{1-\sin \varphi}\right) P_{x}+\frac{2 C \cos \varphi}{1-\sin \varphi}\right] } \\
& \cdot \exp \left[\frac{2 \tan \varphi_{0}(1+\sin \varphi)}{m(1-\sin \varphi)} x\right]-\frac{C_{0}}{\tan \varphi_{0}}, \\
\tau_{x y}= & {\left[C_{0}+\left(\frac{1+\sin \varphi}{1-\sin \varphi}\right) P_{x} \tan \varphi_{0}+\frac{2 C \cos \varphi \tan \varphi_{0}}{1-\sin \varphi}\right] } \\
& \cdot \exp \left[\frac{2 \tan \varphi_{0}(1+\sin \varphi)}{m(1-\sin \varphi)} x\right]-\frac{C_{0}}{\tan \varphi_{0}} .
\end{aligned}
$$

The width of the plastic zone is given by

$$
\begin{aligned}
x_{\mathrm{s}}= & \frac{m}{2 \tan \varphi_{0}}\left(\frac{1-\sin \varphi}{1+\sin \varphi}\right) \\
& \cdot \ln \left[\frac{k_{0} \gamma H+\left(C_{0} / \tan \varphi_{0}\right)}{\left(C_{0} / \tan \varphi_{0}\right)+\left(((1+\sin \varphi) /(1-\sin \varphi)) P_{x}+((2 C \cos \varphi) /(1-\sin \varphi))\right.}\right],
\end{aligned}
$$

where $x_{s}$ is the width of the plastic zone.

2.3.4. The Side Abutment Pressure Distribution in Elastic Zone. The side abutment pressure distribution in the elastic zone follows the negative exponent distribution [8].

$$
\sigma_{y \mathrm{e}}=\chi \exp \left(-\alpha_{0} x\right)+\gamma H\left(x \geq x_{s}\right),
$$


where $\sigma_{y \mathrm{e}}$ is the side abutment pressure in the elastic zone; $\chi$ is the factor to describe the peak side abutment pressure; and $\alpha_{0}$ is the factor to describe the change of the side abutment pressure.

To assure the stress continuum, substituting $x=x_{\mathrm{s}}$ and $f(x)=k_{0} \gamma H$ into (24) yields

$$
\chi=\frac{\left(k_{0}-1\right) \gamma H}{\exp \left(-\alpha_{0} x_{s}\right)} \text {. }
$$

The side abutment pressure in the elastic zone is shown as

$$
\sigma_{y \mathrm{e}}=\left(k_{0}-1\right) \gamma H \exp \left[-\alpha_{0}\left(x-x_{\mathrm{s}}\right)\right]+\gamma H\left(x \geq x_{\mathrm{s}}\right) .
$$

2.3.5. Solving $\alpha_{0}$. The vertical counterforce at the interface should be equal to the weight of the overlying strata.

$$
\gamma H L=\int_{0}^{x_{\mathrm{s}}} \sigma_{y} d x+\int_{x_{\mathrm{s}}}^{L-(b / 2)} \sigma_{y \mathrm{e}} d x .
$$

Submitting (2) and (26) into (27) yields

$$
\begin{gathered}
\frac{\left(k_{0}-1\right) \gamma H}{\alpha_{0}}\left\{1-\exp \left[\alpha\left(x_{\mathrm{s}}-L+\frac{b}{2}\right)\right]\right\}-\frac{C_{0} x_{\mathrm{s}}}{\tan \varphi_{0}}-\gamma H\left(x_{\mathrm{s}}+\frac{b}{2}\right) \\
=-\frac{m}{2}\left[\frac{C_{0}(1-\sin \varphi)}{\tan ^{2} \varphi_{0}(1+\sin \varphi)}+\frac{P_{x}}{\tan \varphi_{0}}\right. \\
\left.+\frac{2 C \cos \varphi}{\tan \varphi_{0}(1+\sin \varphi)}\right]\left\{\exp \left[\frac{2 \tan \varphi_{0}(1+\sin \varphi)}{m(1-\sin \varphi)} x_{\mathrm{s}}\right]-1\right\} .
\end{gathered}
$$

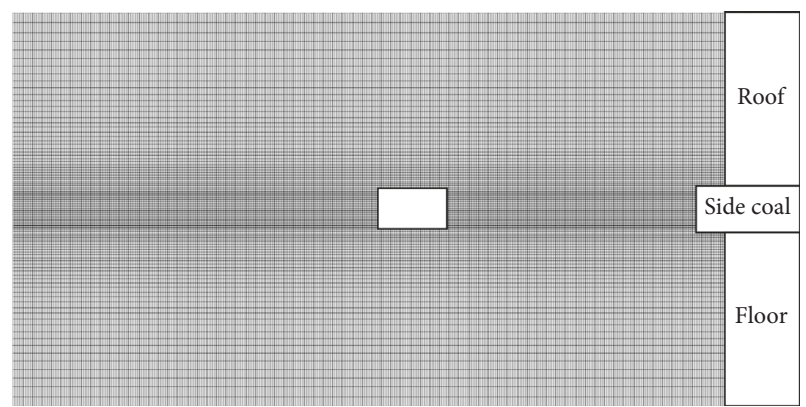

Figure 2: Numerical model.

TABLe 2: Properties of the surrounding rock and the interface.

\begin{tabular}{lcc}
\hline Properties of the surrounding rock & Unit & Value \\
\hline Roof/floor density & $\mathrm{kg} / \mathrm{m}^{3}$ & 2500 \\
Coal density & $\mathrm{kg} / \mathrm{m}^{3}$ & 1300 \\
Roof/floor modulus & $\mathrm{GPa}$ & 10 \\
Coal modulus & $\mathrm{GPa}$ & 4 \\
Roof/floor Poisson ratio & & 0.2 \\
Coal Poisson ratio & $\mathrm{MPa}$ & 0.3 \\
Coal cohesion & $\circ$ & 1 \\
Coal friction angle & $\mathrm{MPa}$ & 25 \\
Coal tension & $\mathrm{unit}$ & 0.5 \\
Properties of the interface & $\mathrm{GPa}$ & Value \\
Normal stiffness & $\mathrm{GPa}$ & 673 \\
Shear stiffness & $\mathrm{MPa}$ & 673 \\
Cohesion & $\circ$ & 0.1 \\
Friction angle & $\mathrm{MPa}$ & 10 \\
Tension & & 0 \\
\hline
\end{tabular}

Substituting (28) into (27) yields

$\alpha_{0}=\frac{\left(k_{0}-1\right) \gamma H}{\left(C_{0} x_{\mathrm{s}} / \tan \varphi_{0}\right)+\gamma H\left(x_{\mathrm{s}}+(b / 2)\right)-(m / 2)\left[\left(\left(C_{0}(1-\sin \varphi)\right) /\left(\tan ^{2} \varphi_{0}(1+\sin \varphi)\right)\right)+\left(P_{x} / \tan \varphi_{0}\right)+\left((2 C \cos \varphi) /\left(\tan \varphi_{0}(1+\sin \varphi)\right)\right)\right]\left\{\exp \left[\left(\left(2 \tan \varphi_{0}(1+\sin \varphi)\right) /(m(1-\sin \varphi))\right) x_{\mathrm{s}}\right]-1\right\}}$

\section{Numerical Validation}

Figure 2 shows the $2 \mathrm{D}$ numerical model used in the present study, using the finite difference program FLAC 3D. It is assumed that the behavior of the roof and floor is linear-elastic, and the coal follows Mohr-Coulomb failure criterion. Embedded interfaces are attached to the zone faces along the coal and the roof/floor. The interface stiffness (normal stiffness $k_{n}$ and tangential stiffness $k_{\mathrm{s}}$ ) is estimated using a rule-of-thumb in which $k_{n}$ and $k_{\mathrm{s}}$ are set to 10 times the equivalent stiffness of the stiffest neighboring zone [16], and the constitutive model is perfectly elastic-plastic and follows Mohr-Coulomb failure criterion.

The numerical model is $100 \mathrm{~m}$ wide in the $x$-direction and $50 \mathrm{~m}$ high in the $z$-direction and consists of approximately 50000 zones. The width and height of roadway are $4.8 \mathrm{~m}$ and $4 \mathrm{~m}$, respectively. The bottom and sides of the model are fixed in displacement and the top is applied with a load of $10 \mathrm{MPa}$.
An anisotropic stress field has been assigned in the model with a lateral earth pressure factor of 1 . The parameters of the surrounding rock and the interface are from a case found in a coal mine in China as shown in Table 2.

The numerical results of the roadway stability are compared with the above closed-form solution, which is shown in Figure 3. Note that $k_{0}$ in the closed-form solution is obtained from the modelling. The following can be seen from Figure 3:

(1) The side abutment pressure can be divided into two areas: plastic zone and elastic zone. In the plastic zone, the side abutment pressure increases from the support strength at the wall surface to the peak pressure at the boundary of the plastic zone and elastic zone. In the elastic zone, the side abutment pressure decreases to the in situ stress gradually.

(2) The width of the plastic zone decreases and the width of the elastic zone increases with the increase of the 

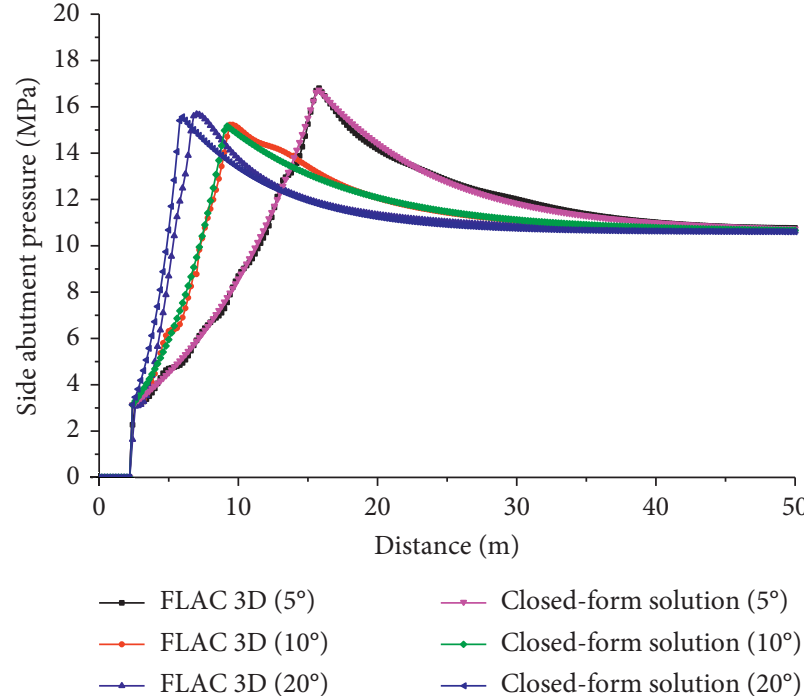

(a)

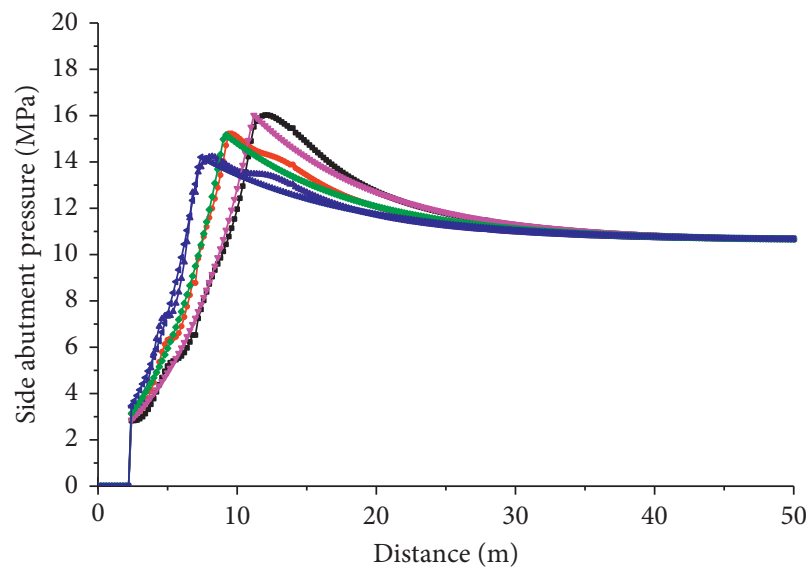

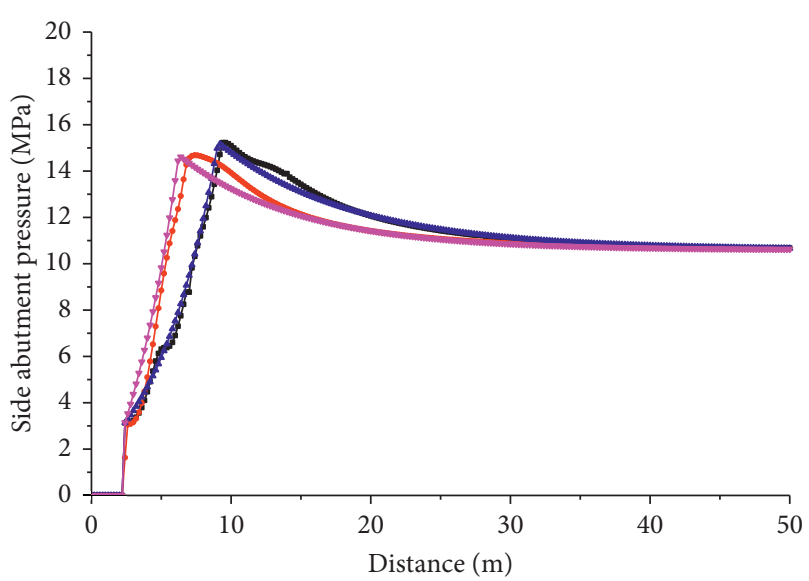

$\rightarrow$ FLAC 3D $(0.1 \mathrm{MPa}) \quad \longrightarrow$ Closed-form solution

- Closed-form solution (1 $\mathrm{MPa})$

(b)
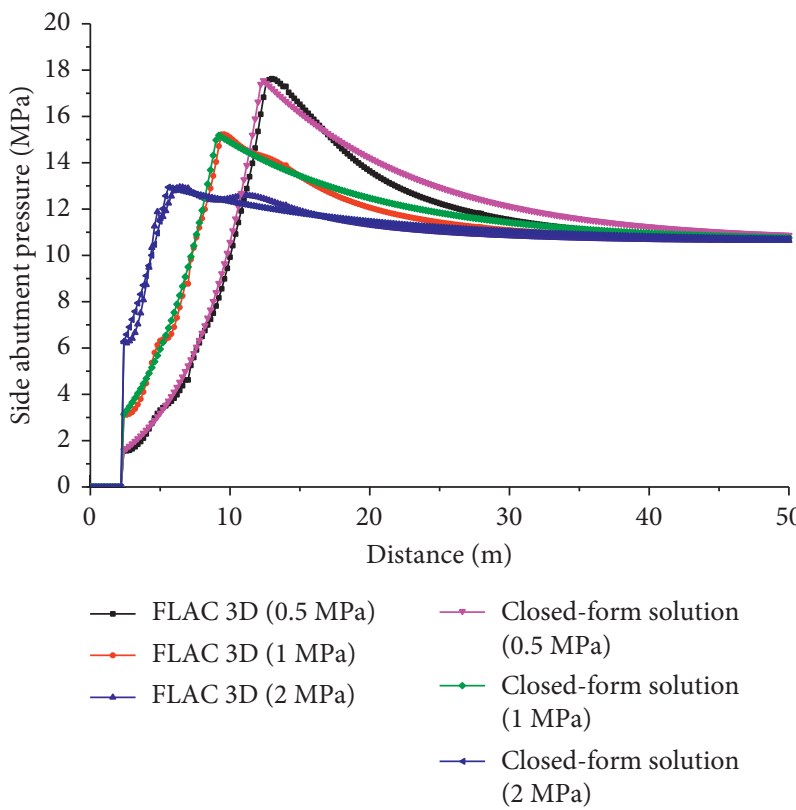

(d)

Figure 3: Continued. 


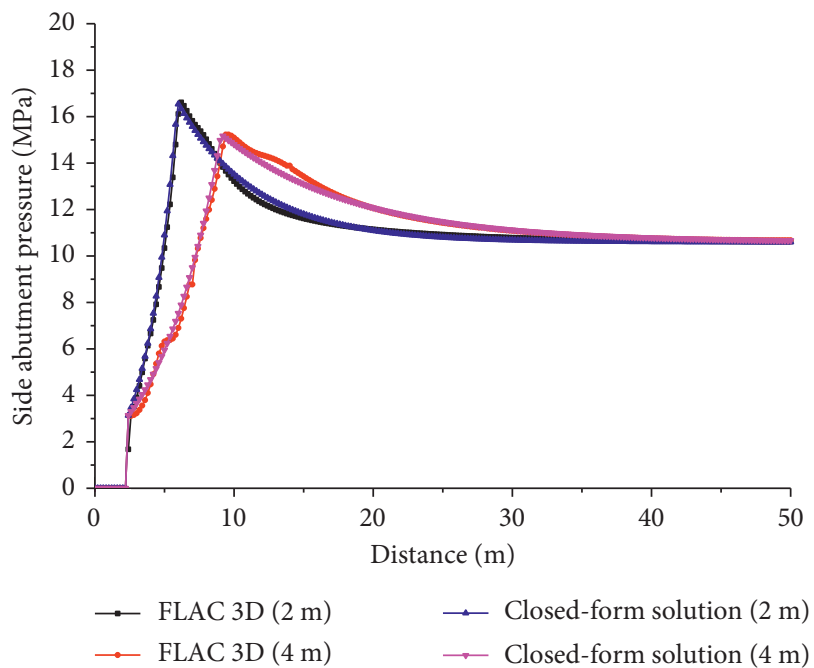

(e)

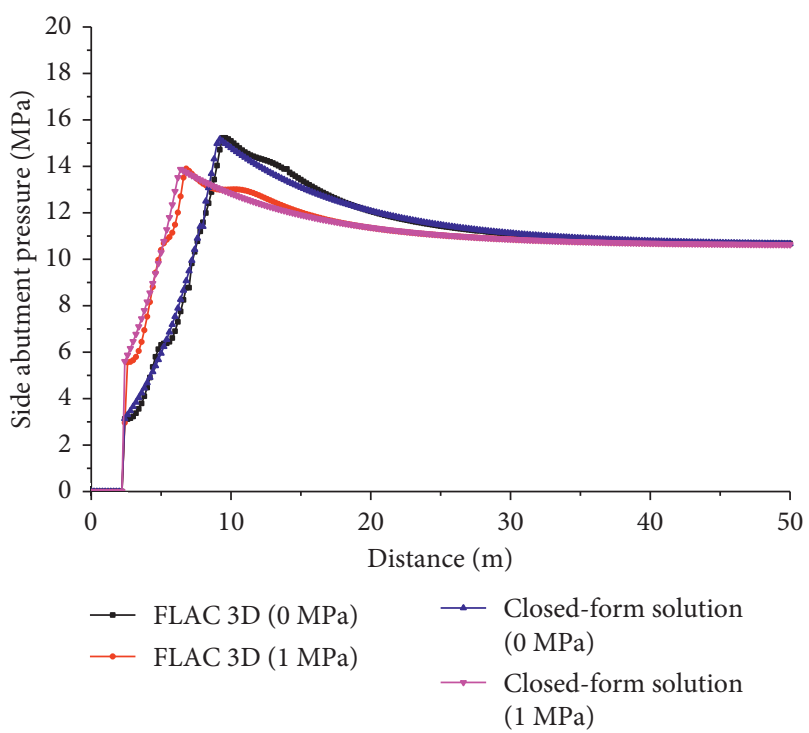

(f)

Figure 3: The side abutment pressure distribution. (a) The interfacial friction angle. (b) The interfacial cohesion. (c) The friction angle of the coal. (d) The cohesion of the coal. (e) The roadway height. (f) The support strength.

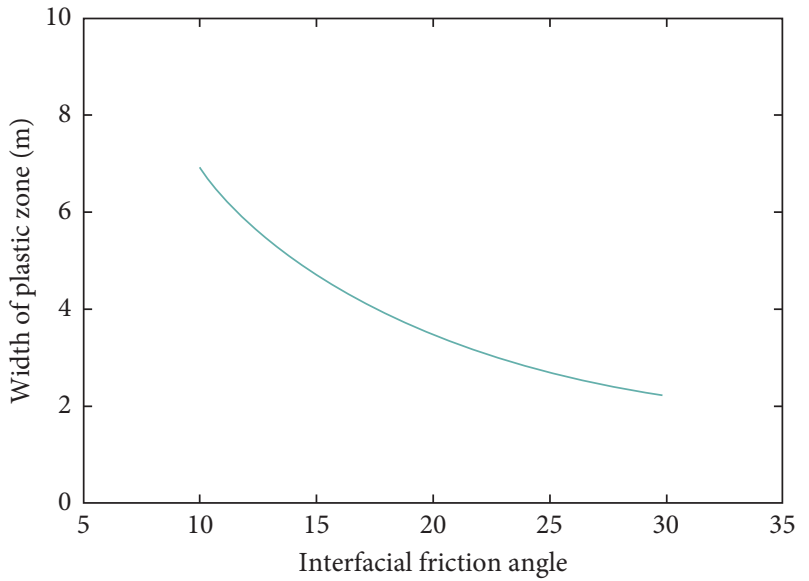

(a)

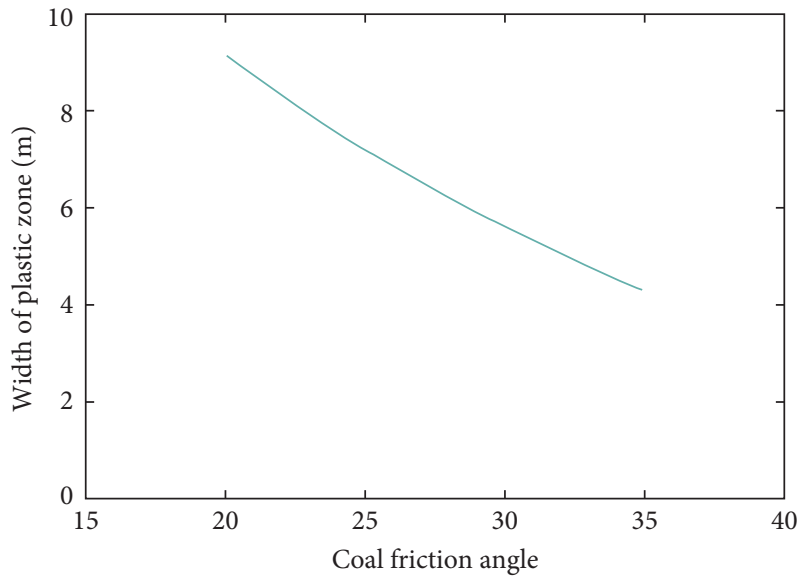

(c)

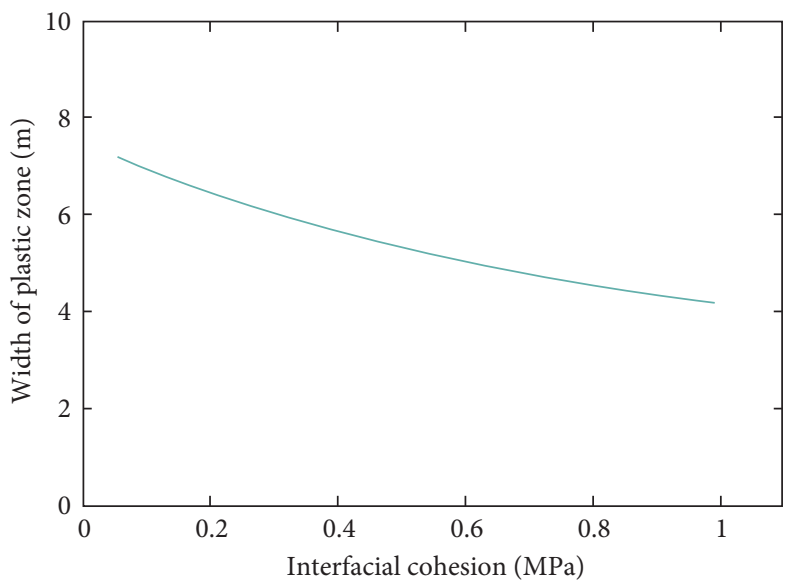

(b)

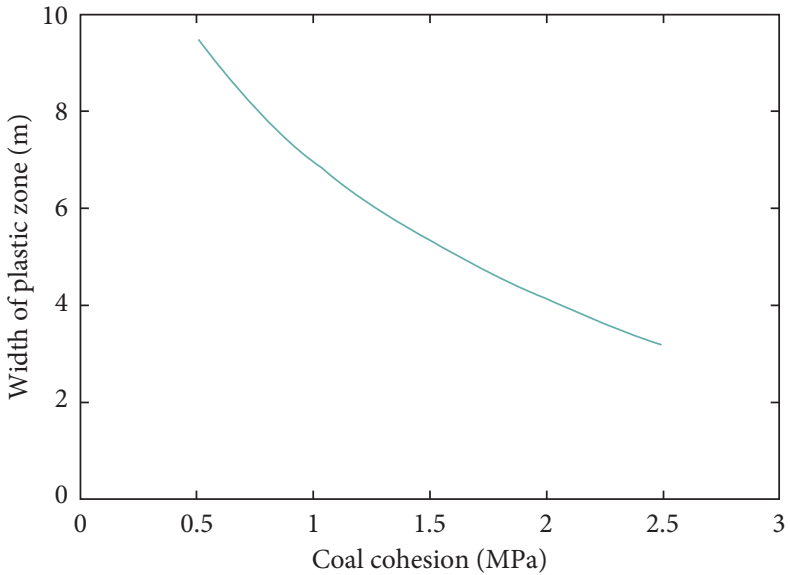

(d)

FIGURE 4: Continued. 


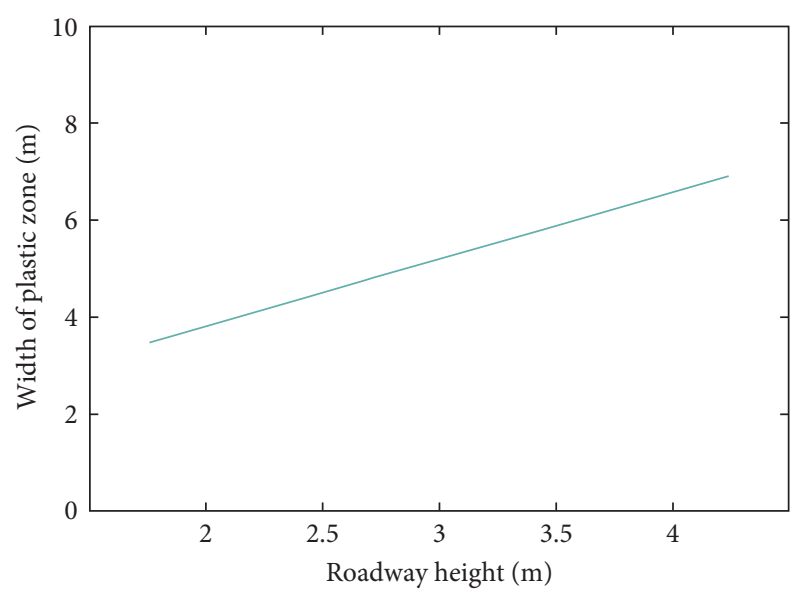

(e)

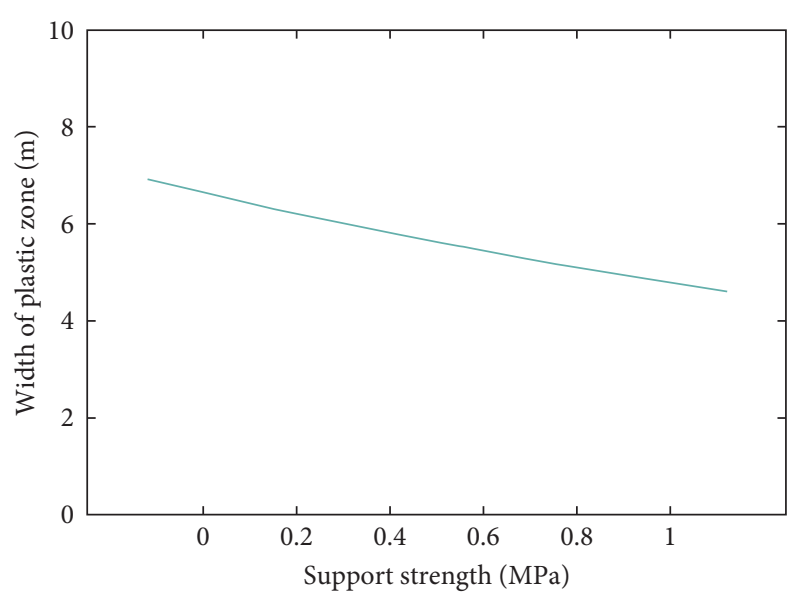

(f)

FIgure 4: Parametric analysis of the width of plastic zone. (a) The interfacial friction angle. (b) The interfacial cohesion. (c) The coal friction angle. (d) The coal cohesion. (e) The roadway height. (f) The support strength.

properties of the coal and the interface, the support strength, and the decrease of the roadway height.

(3) From the comparison between the side abutment pressure of the closed-form solution and FLAC 3D, the numerical results of the side abutment pressure are generally in good agreement with the one obtained using the closed-form solution when changing the properties of the coal and the interface, the roadway height, and the support strength. However, the error between the side abutment pressure of the closedform solution and FLAC $3 \mathrm{D}$ is relatively large when the interfacial cohesion and friction angle are large.

\section{Parametric Analysis of the Width of Plastic Zone}

Based on (23), the influence of the properties of the side coal and the interface, the roadway height and the support strength on the width of the plastic zone is conducted as shown in Figure 4. The initial parameters are the same of Table 2, and the side abutment pressure concentration factor is set as 1.6.

It can be seen from Figure 4 that the width of the plastic zone is nearly negatively linearly correlated with the friction angle from $20^{\circ}$ to $35^{\circ}$ and cohesion from $0.5 \mathrm{MPa}$ to $2.5 \mathrm{MPa}$ of the coal and the interfacial cohesion from $0.02 \mathrm{MPa}$ to $1 \mathrm{MPa}$ and the support strength from $0 \mathrm{MPa}$ to $1 \mathrm{MPa}$. By contrast, it is positively linearly correlated with the roadway height from $2 \mathrm{~m}$ to $4 \mathrm{~m}$ and negatively exponentially correlated with the interfacial friction angle from $10^{\circ}$ to $30^{\circ}$. In roadway support, the support strength is usually less than $0.2 \mathrm{MPa}$, and therefore the support strength has little effect on the width of the plastic zone especially in roadway with hard coals.

\section{Summary and Conclusions}

The side abutment pressure distribution is fundamental to evaluate the roadway stability. The side abutment pressure can be divided into two areas: plastic zone and elastic zone. The side abutment pressure increases in the plastic zone and decreases in the elastic zone. The width of the plastic zone decreases and the width of the elastic zone increases with the increase of the properties of the coal and the interface, the support strength, and the decrease of the roadway height. This paper derived a new closed-form solution which takes into consideration the properties of the side coal and the interface, the roadway height, and the support strength. Moreover, a numerical investigation was conducted to validate the accuracy of the closed-form solution. The numerical results of the side abutment pressure are generally in good agreement with the one obtained using the closed-form solution when changing the properties of the coal and the interface, the roadway height, and the support strength. However, the error between the side abutment pressure of the closed-form solution and FLAC 3D is relatively large when the interfacial cohesion and friction angle are large. The results also show that the effect of the properties of the coal and the interface, the roadway height, and the support strength on the width of the plastic zone in detail when the shallow side coal is subject to plastic state. The results obtained in the present study could be useful for the evaluation process of roadway stability.
Abbreviations
$\sigma_{y}: \quad$ Vertical stress in the plastic zone
$\sigma_{x}: \quad$ Horizontal stress in the plastic zone
$\sigma_{y \mathrm{e}}$ : $\quad$ Vertical stress in the elastic zone
$x_{s}$ : Width of the plastic zone
$L: \quad$ Influence distance of the side abutment pressure
$m$ : Roadway height
b: $\quad$ Roadway width
C: $\quad$ Coal cohesion
$\varphi: \quad$ Coal friction angle
$C_{0}: \quad$ Interfacial cohesion
$\varphi_{0}$ : Interfacial friction angle
$E_{y}$ : $\quad$ Elastic modulus of coal 
$E_{k}$ : $\quad$ Elastic modulus of immediate roof

$k_{0}$ : $\quad$ Side abutment pressure concentration factor

$\gamma$ : $\quad$ Average density of overlying strata

$H$ : $\quad$ Height of overlying strata

Q: $\quad$ Overburden weight over gob transferred to the coal seam

$S_{1}, S_{2}, S_{3}$ : Counterforce of the coal seam

$l_{1}$ : $\quad$ Length of cantilever roof

$\alpha: \quad$ Failure angle of roof

$\beta$ : $\quad$ Dip angle of coal seam

$\eta$ : $\quad$ Lateral earth pressure factor

$\eta(H): \quad$ Depth factor

$f_{n}$ : $\quad$ Strength factor of coal

$f_{c}$ : $\quad$ Strength factor of overburden strata

$\sigma_{c}: \quad$ Uniaxial compressive strength of coal

$P_{x}: \quad$ Support strength

$\phi: \quad$ Roof rotation angle

$y_{0}$ : Roof-floor convergence at the surface of wall rib

$K_{\mathrm{s}}$ : $\quad$ Shear stiffness between coal and rock

$\tau_{x y}: \quad$ Shear stress

$\alpha_{0}$ : $\quad$ Factor to describe the change of the side abutment pressure

$\chi: \quad$ Factor to describe the peak side abutment pressure.

\section{Data Availability}

The data used to support the findings of this study are available from the corresponding author upon request.

\section{Conflicts of Interest}

The authors declare no conflicts of interest.

\section{Acknowledgments}

This study is supported by "The Fundamental Research Funds for the Central Universities" (Grant no. 2017BSCXB49).

\section{References}

[1] Q. Yao, X. Li, B. Sun et al., "Numerical investigation of the effects of coal seam dip angle on coal wall stability," International Journal of Rock Mechanics and Mining Sciences, vol. 100, pp. 298-309, 2017.

[2] W. L. Shen, J. B. Bai, X. Y. Wang et al., "Response and control technology for entry loaded by mining abutment stress of a thick hard roof," International Journal of Rock Mechanics and Mining Sciences, vol. 90, pp. 26-34, 2016.

[3] H. Kang, J. Li, J. Yang, and F. Gao, "Investigation on the influence of abutment pressure on the stability of rock bolt reinforced roof strata through physical and numerical modeling," Rock Mechanics and Rock Engineering, vol. 50, no. 2, pp. 387-401, 2017.

[4] Z. Xu, Elasticity, Higher Education Press, Beijing, China, 4th edition, 2006, in Chinese.

[5] S. Yan, J. Bai, X. Wang, and L. Huo, "An innovative approach for gateroad layout in highly gassy longwall top coal caving," International Journal of Rock Mechanics and Mining Sciences, vol. 59, pp. 33-41, 2013.
[6] A. Suchowerska, J. Carter, and R. Merifield, "Vertical stress changes in multi-seam mining under supercritical longwall panels," International Journal of Rock Mechanics and Mining Sciences, vol. 61, pp. 306-320, 2013.

[7] A. H. Wilson, "The stability of underground workings in the soft rocks of the coal measures," International Journal of Mining Engineering, vol. 1, no. 2, pp. 91-187, 1983.

[8] H. Chen and T. Liu, "Parametric study of the abutment stress of workface," Journal of Xi'an University of Science and Technology, vol. 1, pp. 106-125, 1985, in Chinese.

[9] C. Hou and N. Ma, Theory and Application of Mining Roadways, China Coal Industry Publishing House, Beijing, China, 1st edition, 1994, in Chinese.

[10] Y. Yu, X. Hong, and F. Chen, "Study on load transmission mechanism and limit equilibrium zone of coal-wall in extraction opening," Journal of China Coal Society, vol. 37, pp. 1630-1636, 2012, in Chinese.

[11] K. A. Shou, "A three-dimensional hybrid boundary element method for non-linear analysis of a weak plane near an underground excavation," Tunnelling and Underground Space Technology, vol. 15, no. 2, pp. 215-226, 2000.

[12] S. Jeon, J. Kim, Y. Seo et al., "Effect of a fault and weak plane on the stability of a tunnel in rock-a scaled model test and numerical analysis," International Journal of Rock Mechanics and Mining Sciences, vol. 41, pp. 658-663, 2004.

[13] H. Zhao, M. FengShan, D. Ding et al., "Structural weakness planes effect of roadway surrounding rocks deformation and failure affected by underground mining," Journal of Geological Hazards and Environment Preservation, vol. 20, no. 2, pp. 51-56, 2009.

[14] Z. Zhao, W. Wang, L. Wang et al., "Compression-shear strength criterion of coal-rock combination model considering interface effect," Tunnelling and Underground Space Technology, vol. 47, pp. 193-199, 2015.

[15] W. Shen, J. Bai, and W. Li, "Prediction of relative displacement for entry roof with weak plane under the effect of mining abutment stress," Tunnelling and Underground Space Technology, vol. 71, pp. 309-317, 2018.

[16] Itasca Consulting Group, FLAC Fast Lagrangian Analysis of Continua, Version 4.0, Itasca Consulting Group, Minneapolis, MN, USA, 2009. 


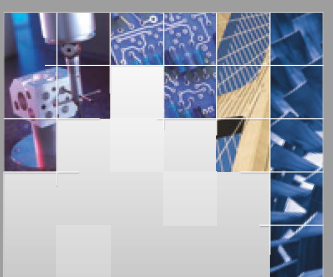

\section{Enfincering}
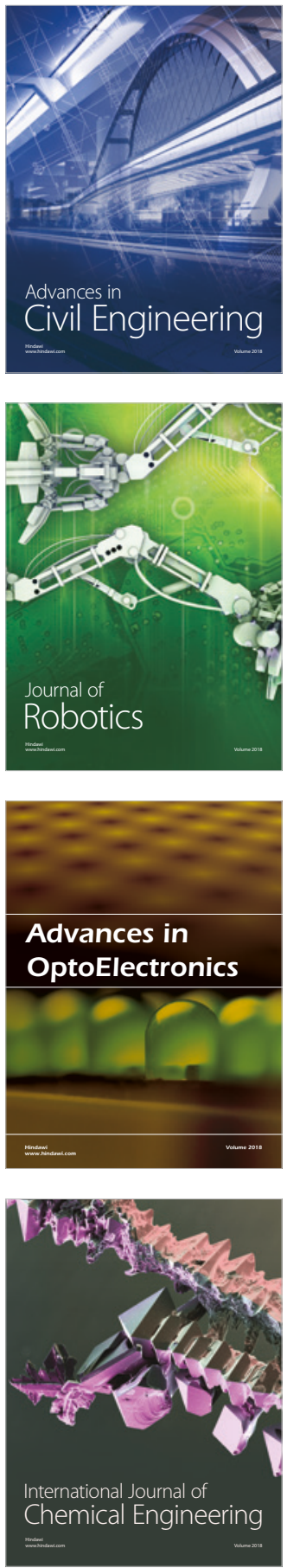

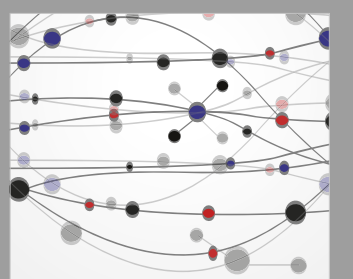

\section{Rotating \\ Machinery}

The Scientific World Journal

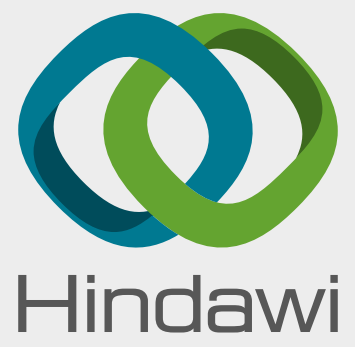

Submit your manuscripts at

www.hindawi.com
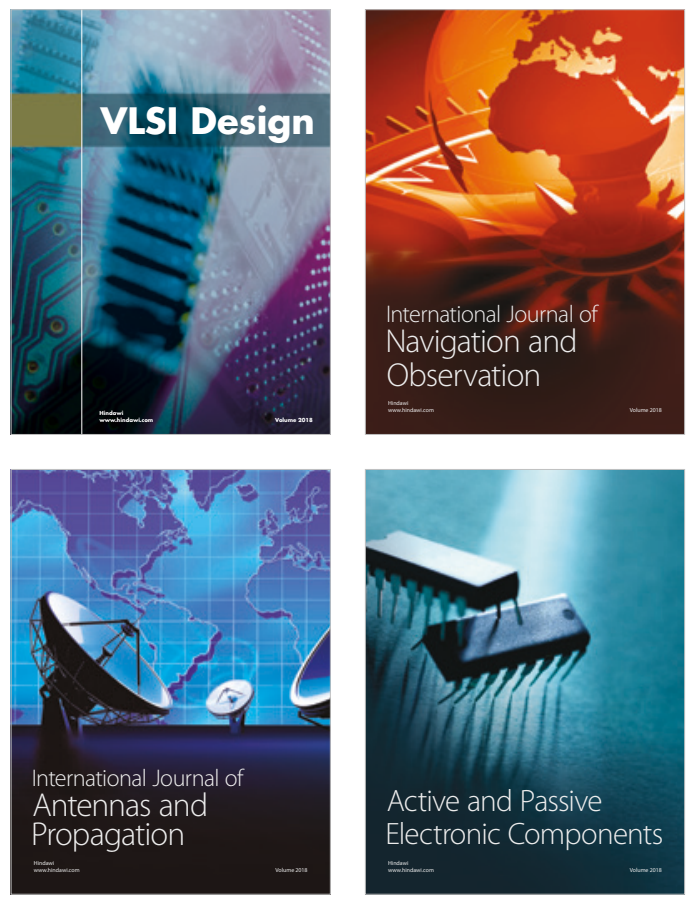
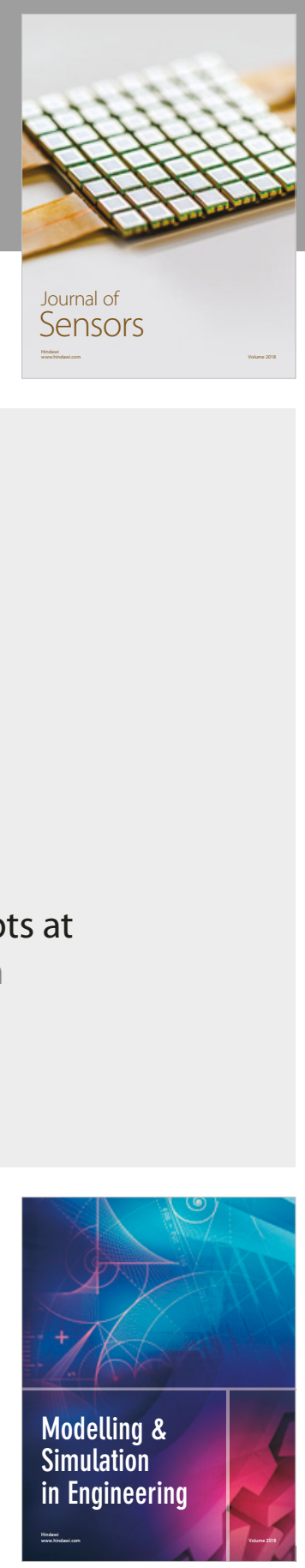

\section{Advances \\ Multimedia}
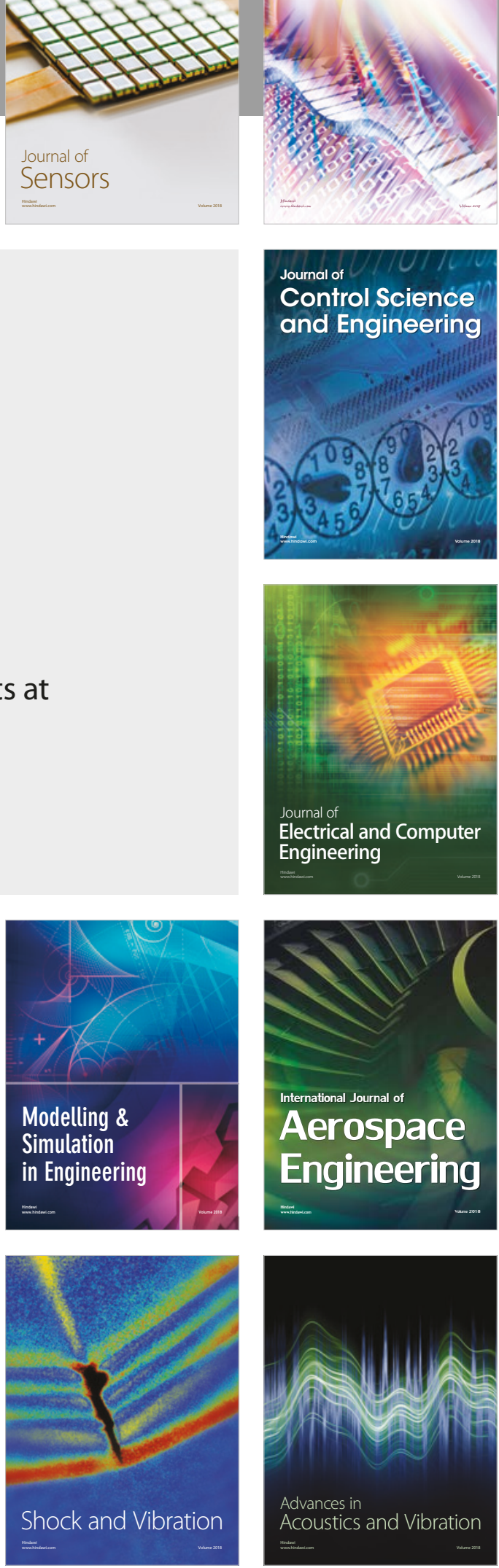